Article

\title{
Bioelectrochemical Properties of Enzyme-Containing Multilayer Polyelectrolyte Microcapsules Modified with Multiwalled Carbon Nanotubes
}

\author{
Anatoly Reshetilov 1,2,*(D), Yulia Plekhanova ${ }^{1, *(D)}$, Sergei Tarasov ${ }^{1,2}$, Sergei Tikhonenko ${ }^{3}$ (D), \\ Alexey Dubrovsky ${ }^{3}$, Alexander Kim ${ }^{3}$, Vadim Kashin ${ }^{2}$, Andrey Machulin ${ }^{1}$, Gou-Jen Wang ${ }^{4}$, \\ Vladimir Kolesov ${ }^{2}$ and Iren Kuznetsova ${ }^{2}$ \\ 1 FSBIS G.K. Skryabin Institute of Biochemistry and Physiology of Microorganisms, \\ Russian Academy of Sciences, Pushchino, Moscow Region 142290, Russia; setar25@gmail.com (S.T.); \\ and.machul@gmail.com (A.M.) \\ 2 FSBIS V.A. Kotelnikov Institute of Radio Engineering and Electronics, Russian Academy of Sciences, \\ Moscow 125009, Russia; vadim_kashin@mail.ru (V.K.); kvv@cplire.ru (V.K.); kuziren@yandex.ru (I.K.) \\ 3 FSBIS Institute of Theoretical and Experimental Biophysics, Russian Academy of Sciences, Pushchino, \\ Moscow Region 142290, Russia; tikhonenkosa@gmail.com (S.T.); Dav198@mail.ru (A.D.); \\ kimerzent@gmail.com (A.K.) \\ 4 Department of Mechanical Engineering, National Chung-Hsing University, Taichung 402, Taiwan; \\ gjwang@dragon.nchu.edu.tw \\ * Correspondence: anatol@ibpm.pushchino.ru (A.R.); plekhanova@ibpm.pushchino.ru (Y.P.)
}

Received: 28 February 2019; Accepted: 11 April 2019; Published: 12 April 2019

\begin{abstract}
This work investigated changes in the biochemical parameters of multilayer membrane structures, emerging at their modification with multiwalled carbon nanotubes (MWCNTs). The structures were represented by polyelectrolyte microcapsules (PMCs) containing glucose oxidase (GOx). PMCs were made using sodium polystyrene sulfonate (polyanion) and poly(allylamine hydrochloride) (polycation). Three compositions were considered: with MWCNTs incorporated between polyelectrolyte layers; with MWCNTs inserted into the hollow of the microcapsule; and with MWCNTs incorporated simultaneously into the hollow and between polyelectrolyte layers. The impedance spectra showed modifications using MWCNTs to cause a significant decrease in the PMC active resistance from 2560 to $25 \mathrm{kOhm}$. The cyclic current-voltage curves featured a current rise at modifications of multilayer MWCNT structures. A PMC-based composition was the basis of a receptor element of an amperometric biosensor. The sensitivity of glucose detection by the biosensor was 0.30 and $0.05 \mu \mathrm{A} / \mathrm{mM}$ for PMCs/MWCNTs/GOx and PMCs/GOx compositions, respectively. The biosensor was insensitive to the presence of ethanol or citric acid in the sample. Polyelectrolyte microcapsules based on a multilayer membrane incorporating the enzyme and MWCNTs can be efficient in developing biosensors and microbial fuel cells.
\end{abstract}

Keywords: multilayer membrane structures; polyelectrolyte microcapsules (PMCs); glucose oxidase; modification with multiwalled carbon nanotubes; PMC impedance decrease

\section{Introduction}

Recent research has witnessed an increased interest in developments of micro- and nanostructures to be used in miniature devices [1]. Microstructures can be developed based on various materials, some of which are frequently used polyelectrolytes [2,3]. Polyelectrolyte microcapsules (PMCs), fabricated by alternate layering of oppositely charged polyelectrolytes to nano- and microsize disperse particles, are subjects of a rapidly developing field of polymer nanotechnology [4-6]. The approach has been 
first described by Decher and coworkers [7,8]. On the whole, polyelectrolyte multilayers/multilayer membranes are widely used in many applications, including biosensors [9-11], asymmetric membranes for gas separation [12], and tissue engineering [13]; they have also been used for antibacterial purposes [14,15].

The PMC multilayer membrane has a protective action on objects inside the capsule, this enables using microcapsules as microcontainers and microreactors in medical [16], light [17,18], and agricultural industries [19]. Enzymes immobilized into polyelectrolyte microcapsules can be used to develop biosensors, e.g., for assaying urea [20-22], acetylcholine [23], and glucose [24].

When forming biosensors and microbial fuel cells (MFCs), an important electrical parameter to be considered is the conductance of measuring electrode material. One of the modern tendencies in choosing electrode materials for MFCs and biosensors is, at present, the use of nanostructured materials for modifying electrodes, which is due to their unique physical and chemical properties [25]. It is known that the modification of the measuring electrode with carbon nanomaterials results in the decrease of its resistance, as well as in the increase of the active surface of the working electrode [26]. The most promising materials for developing bioelectrodes in bioelectrochemistry are carbon nanotubes [27], graphene [28], mesoporous carbon [29], and carbon black [30], owing to their high porosity, surface area, and conductance [31].

The bulk of works on the modification of polyelectrolyte layers with nanomaterials is related to the development of biosensors based on glassy carbon electrodes [32]. In several works [33,34], a composition of glucose oxidase (GOx) and multiwalled carbon nanotubes (MWCNTs) was immobilized into layers of osmium polymers and used as the base for screen-printed amperometric glucose biosensors. Those biosensors demonstrated a good stability and low detection limit but suffered from hindered glucose transport through the multilayers of osmium polymers. As far as we are aware, modifications with carbon nanotubes of closed multilayer membrane structures represented by enzyme-containing PMCs have not been carried out.

The aim of this work was to investigate changes in bioelectrochemical parameters of polyelectrolyte microcapsules formed from multilayer membranes containing the enzyme (GOx) at their modification with multilayer carbon nanotubes.

\section{Materials and Methods}

\subsection{Reagents}

Reagents used: sodium chloride, dipotassium hydrogen phosphate trihydrate, sodium hydroxide, glucose, and acetic acid (Diakon, Russia); iron(III) chloride, potassium chloride, calcium chloride, and sodium carbonate (Khimmed, Russia); hydrochloric acid, hydrogen peroxide (30\% solution), sodium carbonate, and potassium hexacyanoferrate(III) (HCF) (Reakhim, Russia); chitosan (low molecular weight), sodium polystyrene sulfonate (PSS, $70 \mathrm{kDa})$, poly(allylamine hydrochloride) (PAH, $70 \mathrm{kDa})$, ethylenediaminetetraacetic acid (EDTA), and 4-aminoantipyrine, phenol, glucose oxidase (EC 1.1.3.4) from Aspergillus niger (activity, 185000 U/g) (Sigma-Aldrich, USA). Taunit-M multiwalled carbon nanotubes (NanoTechCentre LLC, Tambov, Russia) were used for modification of the electrode.

Screen-printed three-contact electrodes (Color Electronics, Moscow, Russia) containing Electrodag 6017SS graphite paste (Henkel, Germany) were used.

\subsection{Formation of a Prussian Blue-Based Chemical Sensor}

Prussian blue was precipitated on the electrode surface from the reaction mixture containing $0.1 \mathrm{M} \mathrm{FeCl}_{3}$ and $0.1 \mathrm{M} \mathrm{K}_{3}\left[\mathrm{Fe}(\mathrm{CN})_{6}\right]$ in the background electrolyte $(0.1 \mathrm{M} \mathrm{KCl}, 0.1 \mathrm{M} \mathrm{HCl})$. The mixture was preliminarily kept for $20 \mathrm{~min}$ in an Eppendorf test tube in the dark; then it was applied onto the working electrode. After $15 \mathrm{~min}$, hydrogen peroxide was added into the applied solution to a concentration of $100 \mathrm{mM}$ in a drop; the produced mixture was held on the electrode for $45 \mathrm{~min}$. Upon precipitation, the electrode surface was washed with Milli-Q water. After that the electrode was activated (a potentiodynamic treatment of the Prussian blue electrode in a cyclic mode in the 
background electrolyte from -0.05 up to $0.35 \mathrm{~V}$ ) in accordance with the method described by Karyakin and co-authors [35].

In special experiments, the surface of the graphite electrode was modified with MWCNTs prior to the precipitation of Prussian blue. For this, a suspension of nanotubes $(5 \mathrm{mg} / \mathrm{mL})$ was applied onto the electrode surface and dried for $1 \mathrm{~h}$ at $22^{\circ} \mathrm{C}$.

\subsection{Formation of $\mathrm{CaCO}_{3}$-Protein Microspherolites}

For the preparation of microcapsules, an equal volume of a sodium carbonate solution $(0.33 \mathrm{M})$ was added to a $0.33 \mathrm{M}$ calcium chloride solution and intensively stirred on a magnetic mixer. The mixing was continued for $30 \mathrm{~s}$, after which the suspension was kept up to the complete sedimentation of formed particles [36]. Maturation of microspherolites was monitored by a light microscope. Then the solution was filtered from the supernatant, the sediment was washed with distilled water and used to produce PMCs.

For the preparation of microcapsules containing GOx, an equal volume of a sodium carbonate solution $(0.33 \mathrm{M})$ was added to a $0.33 \mathrm{M}$ calcium chloride solution containing $3 \mathrm{mg} / \mathrm{mL}$ GOx and intensively stirred on a magnetic mixer.

To produce microcapsules containing MWCNTs in the hollow, a suspension of nanotubes was mixed with a solution of $\mathrm{CaCl}_{2}$.

To produce microcapsules containing MWCNTs in the hollow and GOx simultaneously, a suspension of nanotubes was mixed with a solution of $\mathrm{Na}_{2} \mathrm{CO}_{3}$, and an enzyme solution was mixed with a solution of $\mathrm{CaCl}_{2}$. Further on, from these mixtures we formed composite microspherolites of various structures $\left(\mathrm{CaCO}_{3} ; \mathrm{CaCO}_{3} / \mathrm{GOx} ; \mathrm{CaCO}_{3} / \mathrm{MWCNTs} ; \mathrm{CaCO}_{3} / \mathrm{GOx} / \mathrm{MWCNTs}\right)$ by the above-described technique.

\subsection{Preparation of PMCs}

Polyelectrolyte microcapsules were obtained by alternate adsorption of oppositely charged polyelectrolytes on disperse microparticles (cores) with subsequent dissolution of the cores. Alternate adsorption of PAH and PSS on the surfaces of $\mathrm{CaCO}_{3}$ microspherolites was carried out in polyelectrolyte solutions $(2 \mathrm{mg} / \mathrm{ml})$ containing $0.5 \mathrm{M} \mathrm{NaCl}$. Each adsorption step was followed by a triple washing of fabricated capsules with a $0.5 \mathrm{M} \mathrm{NaCl}$ solution, which was required to discard nonadsorbed polymer molecules. The supernatant was centrifuged to separate the particles. After the required number of layers was deposited, carbonate cores were dissolved for $12 \mathrm{~h}$ in a $0.2 \mathrm{M}$ solution of EDTA. Polyelectrolyte capsules were rinsed three times with Milli-Q to remove cores' components. Capsules contained six polyelectrolyte layers because capsules with fewer layers were unstable. The suspension of capsules was stored in bidistilled water at a temperature of $4{ }^{\circ} \mathrm{C}$.

For the preparation of PMCs/MWCNTs between layers of the polyelectrolytes, microspherolites with two layers of PAH and one layer of PSS were put into a suspension of nanotubes. After 5 min, the microspherolites were washed three times in a $0.5 \mathrm{M} \mathrm{NaCl}$ solution, then the remaining three layers of PAH and PSS were added.

Formation of PMCs around the enzyme is shown schematically in Figure 1.

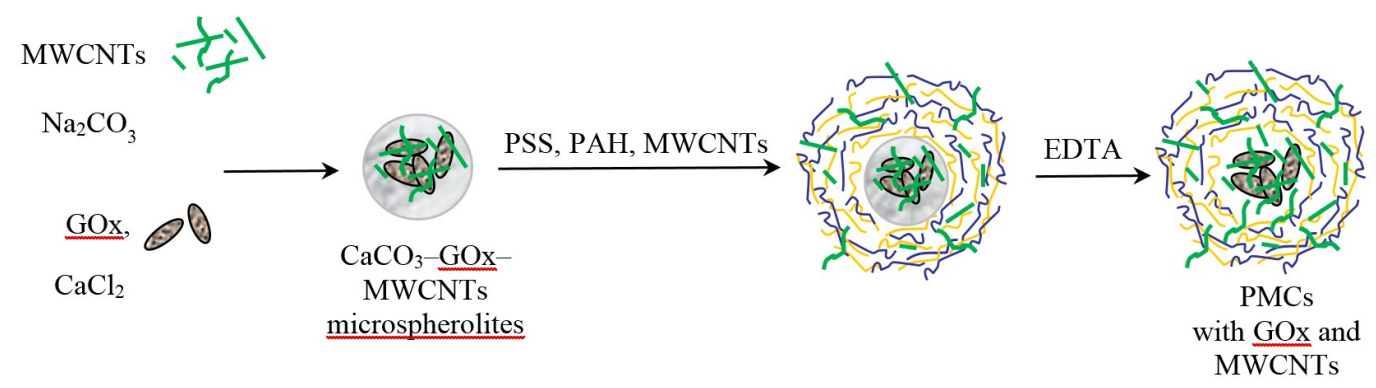

Figure 1. Formation of polyelectrolyte microcapsules with the enzyme and nanotubes. 


\subsection{Formation of Glucose Biosensors}

Polyelectrolyte microcapsules, in the amount of $5 \mu \mathrm{L}$ with incorporated GOx, were applied onto the surface of a Prussian blue electrode and dried at $22^{\circ} \mathrm{C}$ for $30 \mathrm{~min}$. Between measurements, the biosensors were stored at a temperature of $4{ }^{\circ} \mathrm{C}$ in the dark. The measurements were carried out at a temperature of $22^{\circ} \mathrm{C}$ in a 1-ml cell at constant stirring. The measurements were performed on an IPC-Micro galvanopotentiostat (Kronas Ltd, Russia). Glucose solutions were prepared in a $25 \mathrm{mM}$ sodium-potassium-phosphate buffer solution ( $\mathrm{pH}$ 6.5) with the addition of $20 \mathrm{mM} \mathrm{NaCl}$.

The voltammetric and impedance measurements were carried out with a VersaSTAT 4 potentiostat galvanostat (Ametek Inc., USA) in the same solution with the addition of $5 \mathrm{mM}\left[\mathrm{Fe}(\mathrm{CN})_{6}\right]_{3}$. A scanning rate of $40 \mathrm{mV} / \mathrm{s}$ was used for voltammetric measurements. A $100 \mathrm{mV}$ constant potential $(40 \mathrm{kHz}-0.02 \mathrm{~Hz}$ frequency range) and a voltage modulation of $10 \mathrm{mV}$ were used to obtain impedance spectra. The correct equivalent circuit for every system was picked using ZSimpWin software (EChem Software, USA). The measurements were carried out with constant stirring of solutions.

\subsection{Optical Microscopy}

The optical microscopy examination of PMCs was conducted in the phase contrast mode using a Nikon Eclipse Ci microscope (Nikon, Japan) with an image registration camera ProgRes SpeedXT core5 (Jenoptik, Germany). The size of microcapsules was calculated from the average measured sizes of 100 capsules.

\subsection{Scanning Electron Microscopy}

PMCs were dehydrated in a series of alcohols of increasing concentrations (from 50 up to 100\%) for $20 \mathrm{~min}$ at each stage. Then they were suspended in tert-butanol (Sigma-Aldrich) two times for $20 \mathrm{~min}$ each at $26^{\circ} \mathrm{C}$. Further on, the PMCs were held in tert-butanol for $12 \mathrm{~h}$ at $4{ }^{\circ} \mathrm{C}$. The specimens were then freeze-dried (JFD-320, JEOL, Japan). An adhesive tape was used for the preparation of open capsules.

The dried specimens of both types were fixed on aluminium disks by means of a current-conducting tape and coated with gold using a vacuum sputtering equipment JFC-1100 (JEOL, Japan) for better resolution. The specimens were examined in a JSM-6510LV scanning electron microscope (JEOL, Japan).

\subsection{Atomic Force Microscopy}

Freshly cleaved supports from highly oriented pyrolytic graphite (HOPG) were used to investigate PMCs by atomic force microscopy (AFM) methods. The upper layers of HOPG were cleaved directly in a PMC-containing solution. The studies were carried out by a Solver $\mathrm{P} 47 \mathrm{H}$ scanning probe microscope (NT-MDT, Russia) in the semicontact mode in air using a diamond cantilever.

\section{Results}

\subsection{Characterization of PMCs by AFM and SEM}

Micrographs of structures that characterize the composite-electrode material are shown in Figure 2. Figure 2a presents a PMC layer applied to the freshly cleaved surface of HOPG, where both single and aggregated PMCs are seen. The shape and profile of a single microcapsule are shown in Figure 2b,c, respectively. The size of a single PMC was of the order of $2.5 \pm 0.6 \mu \mathrm{m}$ (based on 30 measurements).

PMC micrographs obtained by phase-contrast and scanning electron microscopies are shown in Figure 3. 


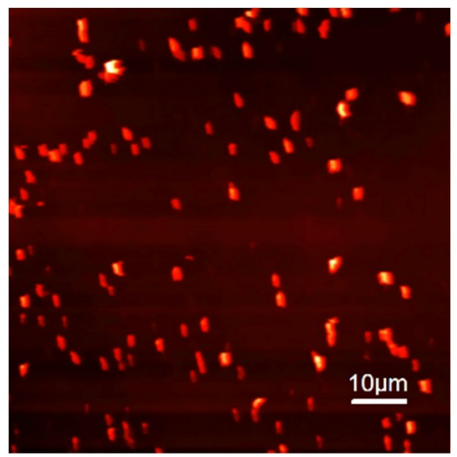

(a)

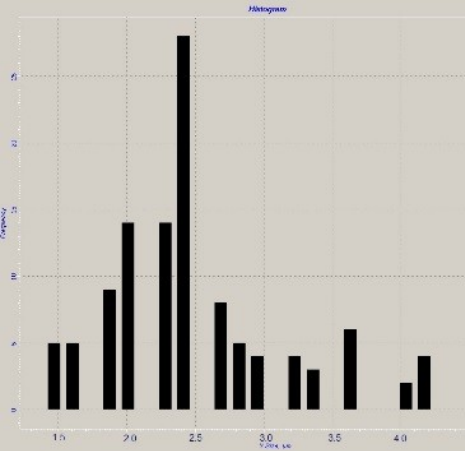

(b)

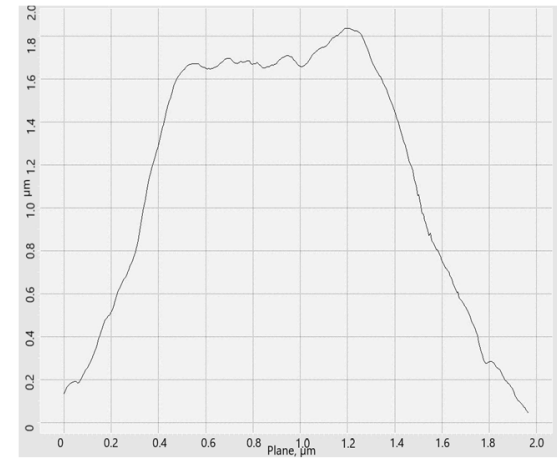

(c)

Figure 2. Atomic force microscopy (AFM) images of microcapsules. An AFM micrograph of a layer of aggregated and single polyelectrolyte microcapsules (PMCs) (a); a histogram of 100 microcapsules (b); and the geometric size of a single microcapsule (c).

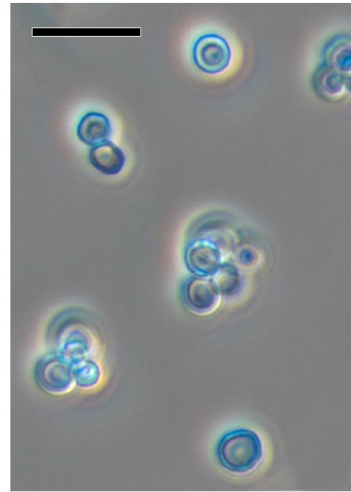

(a)

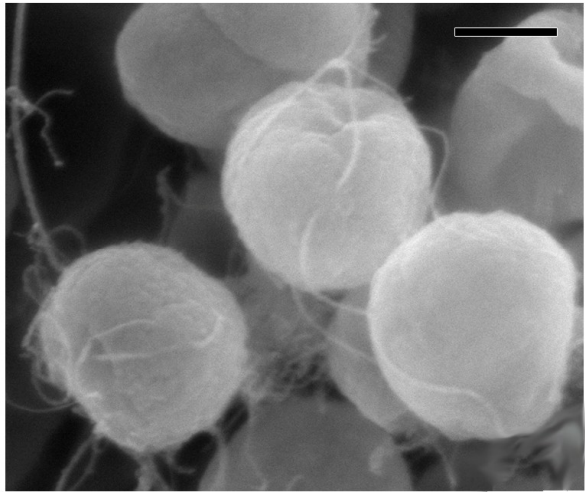

(b)

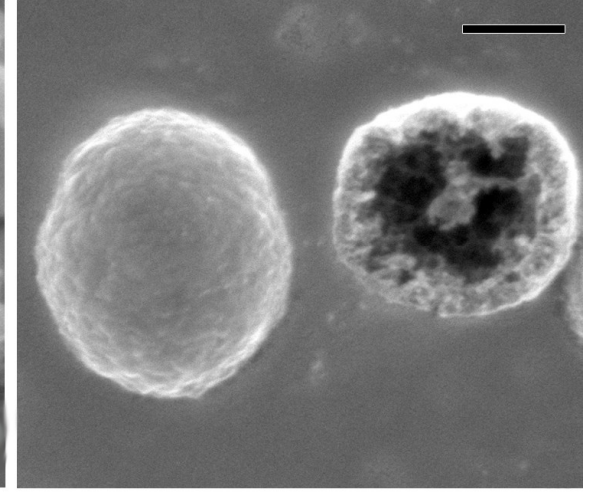

(c)

Figure 3. PMC micrographs obtained by phase-contrast microscopy (a) and scanning electron microscopy ((b) intact capsules and (c) open capsules). Scale bars are $10 \mu \mathrm{m}$ (a) or $1 \mu \mathrm{m}(\mathbf{b}, \mathbf{c})$.

The size of a single microcapsule was of the order of $2.8 \pm 0.5 \mu \mathrm{m}$ (based on 50 measurements). This estimate coincides with that for a single microcapsule shown in Figure 2b. It is seen in Figure $3 a$ that a minor conjugation of PMCs takes place. Figure $3 b, c$ gives an idea of the PMC structure. The thickness of the multilayer membrane consisting of six layers of oppositely charged polyelectrolytes was $37 \pm 3 \mathrm{~nm}$ (each layer was $\sim 6 \mathrm{~nm}$ ) as described by Kazakova and co-authors [37]. Noteworthy is the spatial arrangement of MWCNT threads. Figure $3 c$ shows a case when MWCNTs were incorporated simultaneously between layers of polyelectrolytes and into the hollow of a microcapsule. MWCNT threads partially protruding to the PMC surface are seen.

\subsection{Impedance Characteristics of Various Types of Electrodes}

The impedance of the electrode depends on a multitude of factors; herewith, it changes at the application of any substance onto the electrode surface. Measurements were carried out using electrochemical impedance spectroscopy by the three-electrode scheme in the presence of $5 \mathrm{mM}$ hexacyanoferrate at an applied potential of $100 \mathrm{mV}$. The composition of the solution remained invariable, so any changes in the impedance spectra were related only to the modification of the electrode surface. The impedance spectra for the control states (a nonmodified screen-printed electrode without any coating or electrodes with a coating of PMCs, GOx, PMCs/GOx, and MWCNTs) and MWCNT-modified (PMCs/MWCNTs in the hollow of the PMCs and between polyelectrolyte layers, PMCs containing MWCNTs between polyelectrolyte layers, PMCs containing MWCNTs in the hollow, PMCs containing GOx, and MWCNTs in the hollow) are presented in Figure 4. For convenience of comparison, the frequency impedance curves are given in logarithmic coordinates. The impedance 
spectra were processed using a Randles modified scheme with a constant phase element (CPE) replacing the capacitance of the electrical layer (Figure 4, Inset A). It should be noted that the typical form of the frequency impedance curves changed when a PMC layer was present on the surface of the electrode. We observed two semicircles, each of which featured a separate pair of CPEs and a charge-transfer resistance $R_{\mathrm{ct}}$, instead of one semicircle on the frequency curve (Figure 4, Inset B).

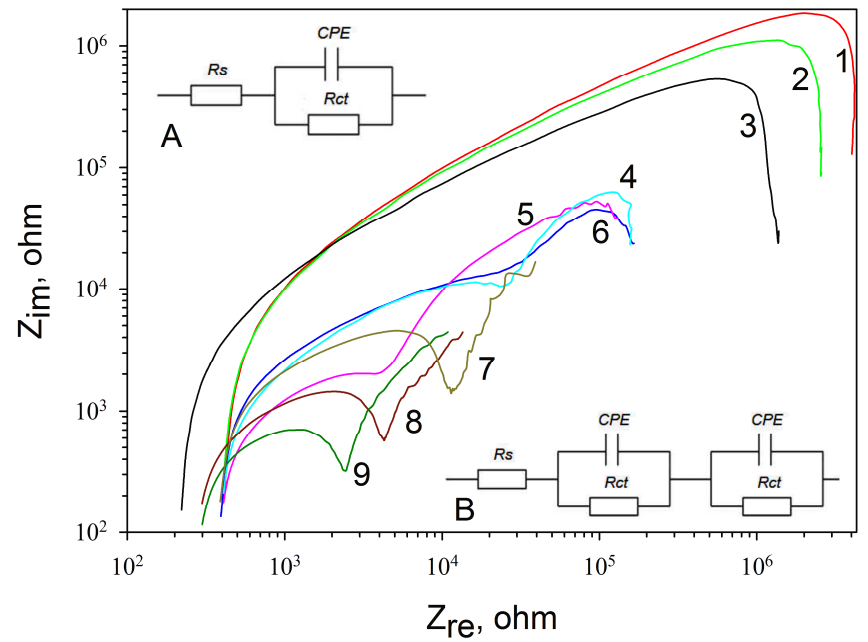

Figure 4. Impedance spectra for electrodes with various surface modifications: 1, a nonmodified electrode; 2, with PMCs; 3, glucose oxidase (GOx); 4, PMCs containing multiwalled carbon nanotubes (MWCNTs) in the hollow and between polyelectrolyte layers; 5, PMCs containing MWCNTs between polyelectrolyte layers; 6, PMCs containing MWCNTs in the hollow; 7, PMCs with GOx; 8, MWCNTs; and 9, PMCs with GOx and MWCNTs in the hollow. Inset shows the equivalent electric circuits used for electrodes without MWCNTs (A) and for electrodes with MWCNTs (B).

The values of active resistances obtained for each modification of the electrode are given in Table 1. The highest resistance values were obtained for screen-printed electrodes without applying any coatings, as well as for electrodes modified separately by the enzyme and PMCs. The lowest value of the resistance was observed for a composition including PMCs, GOx, and MWCNTs in the hollow and between polyelectrolyte layers. Herewith, the resistance was found to decrease from 120 to $25 \mathrm{kOhm}$ as compared with the composition with PMCs/GOx without MWCNTs. Thus, it can be concluded that the incorporation of MWCNTs into PMCs contributes to a better electron transfer in the system, which, in turn, has a positive effect on the characteristics of biosensors based on PMCs/GOx/MWCNTs.

Table 1. Active resistances of screen-printed electrodes with various modifications of the surface.

\begin{tabular}{cc}
\hline Graphite Electrodes Modified with Various Components & Total Resistance, $\mathbf{k O h m}$ \\
\hline Nonmodified screen-printed electrodes & $4200 \pm 200$ \\
\hline PMCs & $2560 \pm 170$ \\
\hline PMCs/MWCNTs in the hollow & $172 \pm 8$ \\
\hline PMCs/MWCNTs in the hollow and between layers of polyelectrolytes & $181 \pm 6$ \\
\hline GOx & $162 \pm 6$ \\
\hline MWCNTs & $34 \pm 0 \pm 30$ \\
\hline PMCs with GOx & $120 \pm 4$ \\
\hline PMCs with GOx and MWCNTs in the hollow and between layers of \\
polyelectrolytes
\end{tabular}

Note: the mean values of five measurements and a mean root square deviation for the total active resistances are given. 


\subsection{Cyclic Voltammograms of Modified Electrodes}

For each modification of the electrode surface cyclic voltammograms were recorded (Figure 5). As the recordings show (Figure 5b, curves 1-6), modifications of the graphite electrode with PMCs at an addition of MWCNTs, both in the hollow and between polyelectrolyte layers, has no significant effect on the cyclic voltammogram shapes. Modification of PMCs with the enzyme has no effect on the voltammograms either. Their shape changes significantly at a modification of the electrode surface with MWCNTs (Figure 5a, curve 8). The changes are due to the emergence of characteristic redox peaks. The values of the peaks decrease significantly at the modification of the electrode surface with PMCs with the enzyme (curve 7); they rise again-but fail to reach the initial value-at addition of microcapsules with enzyme-containing MWCNTs into the hollow (curve 9). Thus, the electrochemical measurements prove a decrease of resistance in the system at its modification with nanotubes. This is supported by both the impedance data and the cyclic voltammograms of the considered electrodes.

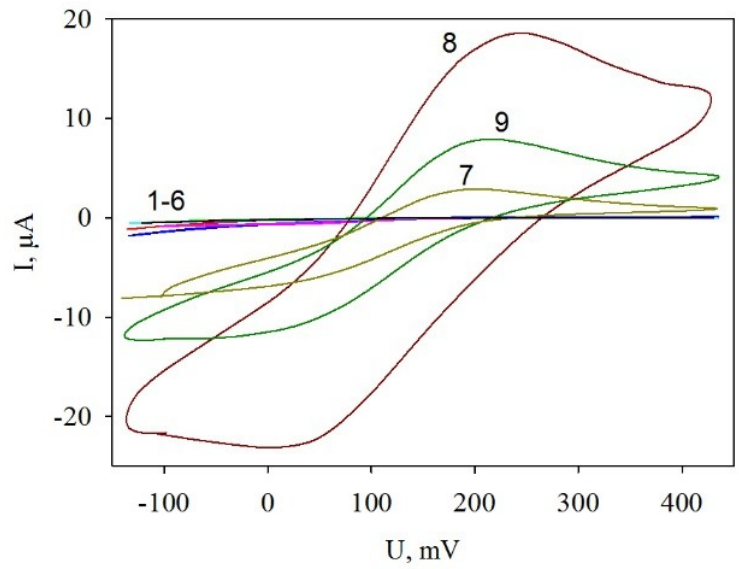

(a)

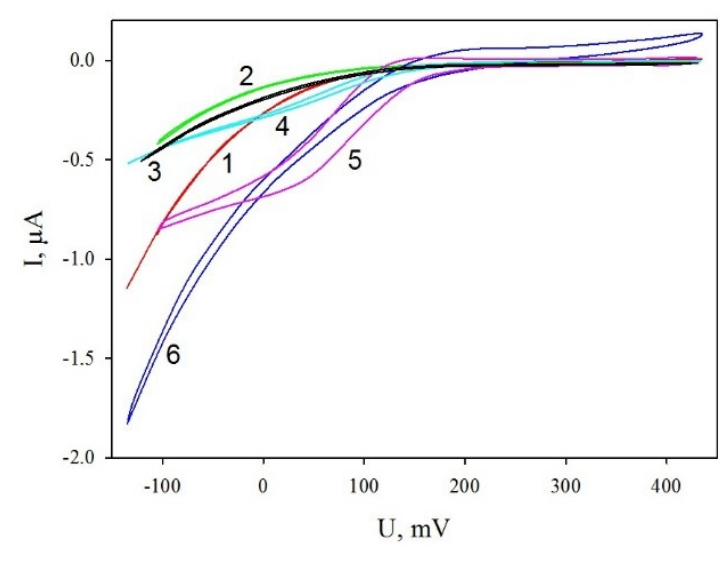

(b)

Figure 5. Cyclic voltammograms of modified electrodes: 1 , a nonmodified electrode; 2 , with PMCs, 3, GOx; 4, PMCs containing MWCNTs in the hollow and between polyelectrolyte layers; 5, PMCs containing MWCNTs between polyelectrolyte layers; 6, PMCs containing MWCNTs in the hollow; 7, PMCs with GOx; 8, MWCNTs; and 9, PMCs with GOx and MWCNTs in the hollow. Measurements were carried out with the addition of $5 \mathrm{mM} \mathrm{HCF}$. For comparison, a shows all types of dependences, while $\mathbf{b}$ represents the zoom of curves 1-6.

Microcapsules with the enzyme were immobilized by sorption on the graphite-electrode surface. The upper layer of polyelectrolyte covering the capsule carries a negative charge and sorbs well on the surface of the graphite electrode owing to Coulomb interaction. To investigate the characteristics of glucose biosensors, the electrode surface was preliminarily modified with Prussian blue. Prussian blue is an electrocatalyst of the reduction of hydrogen peroxide [38,39], which evolves during the oxidation of substrate (glucose) by the enzyme and reflects the catalytic activity of the immobilized enzyme [35].

\subsection{Determination of Kinetic Parameters of PMC/GOx and PMC/GOx/MWCNTs Biosensors}

We investigated the characteristics of biosensors based on electrodes with Prussian blue, modified with enzyme-containing PMCs. Capsules with and without MWCNTs in their composition were used. For comparison, we used GOx immobilized by simple sorption on the surface of the electrode. Figure 6 shows the obtained calibration dependences for the biosensors, Table 2 presents the numerical values of the main characteristics. Introduction of MWCNTs into the capsules leads to higher sensitivity of the biosensor to glucose $(0.30 \mu \mathrm{A} / \mathrm{mM}$ vs. $0.05 \mu \mathrm{A} / \mathrm{mM})$ at the same concentration of the enzyme on the electrode (Figure 6, curves 2 and 3). Additional modification of the electrode surface with nanotubes leads to a further increase of biosensor signals (Figure 6, curve 4) and a significant (up to $0.94 \mu \mathrm{A} / \mathrm{mM}$ ) assay sensitivity increase. This is due to an increase of the conductivity of the system 
and a possible facilitated transfer of electrons from the nanotubes to the electrode, which is also supported by the data of impedance measurements. Besides, a modification of the electrode with MWCNTs changes the glucose detection range (Table 2). The lower range of detection is shifted towards lower concentrations, which are $0.05 \mathrm{mM}$, which enables assaying lower concentrations of glucose. Table 3 presents an overview of GOx-based biosensors for glucose detection. The attained results, coupled with the relative simplicity of the biosensor construction, compare favorably with previously reported biosensors. No study regarding glucose quantification based on PMC/GOx/MWCNTs s-based biosensors was found.

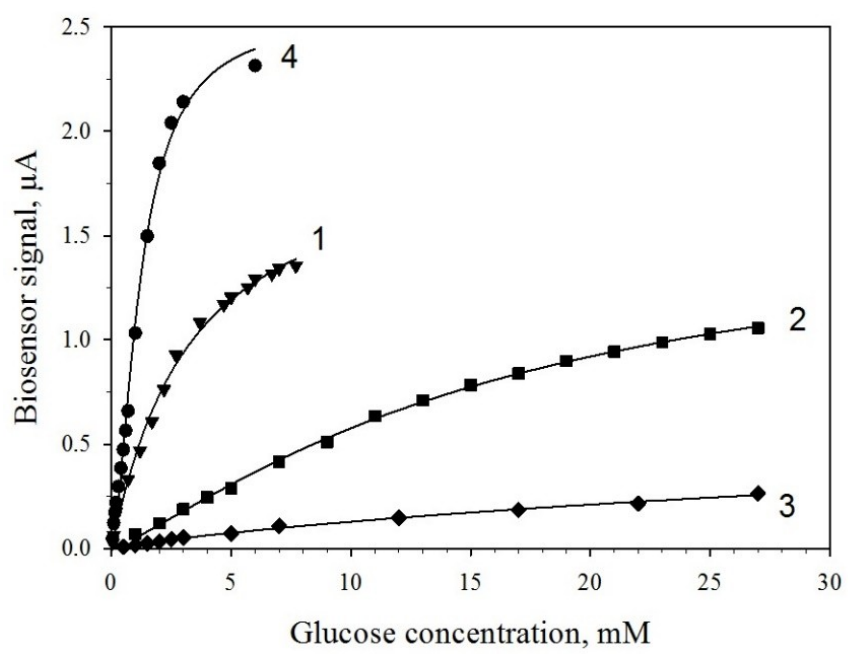

Figure 6. Calibration dependences of biosensor signals vs. glucose concentrations at various modifications of the electrode: 1, PMCs/GOx/MWCNTs in the hollow; 2, PMCs/GOx; 3, GOx; and 4, PMCs/GOx/MWCNTs in the hollow plus an additional modification of the electrode with MWCNTs (see explanations in the text).

Table 2. Basic analytical characteristics of biosensors.

\begin{tabular}{|c|c|c|c|c|}
\hline $\begin{array}{ll}\text { Parameter } & \text { Composition of Biocatalyst } \\
\end{array}$ & PMCs/GOx/MWCNTs * & PMCs/GOx/MWCNTs & PMCs/GOx & GOx \\
\hline $\begin{array}{l}\text { Equation describing the calibration } \\
\text { dependence }\end{array}$ & & $V=\frac{V_{\max } S^{h}}{K_{M}^{h}+S^{h}}$ & & \\
\hline $\begin{array}{l}\text { Parameter values of the calibration } \\
\text { dependence }\end{array}$ & $\begin{array}{c}V_{\max }=2.560 \\
h=1.667 \\
K_{\mathrm{m}}=1.203 \\
R^{2}=0.99\end{array}$ & $\begin{array}{c}V_{\max }=1.938 \\
h=1.050 \\
K_{\mathrm{m}}=3.194 \\
R^{2}=0.99\end{array}$ & $\begin{array}{c}V_{\max }=1.639 \\
h=1.238 \\
K_{\mathrm{m}}=16.393 \\
R^{2}=0.99\end{array}$ & $\begin{array}{c}V_{\max }=0.959 \\
h=0.865 ; \\
K_{\mathrm{m}}=86.692 \\
R^{2}=0.99\end{array}$ \\
\hline Linear range of detection, $\mathrm{mM}$ & $0.05-2$ & $0.2-2.7$ & $1-15$ & $0.5-7$ \\
\hline $\begin{array}{l}\text { Regression equation for the linear segment, } \\
\text { correlation coefficient } R^{2}\end{array}$ & $\begin{array}{c}y=0.9443 x+0.0193 \\
R^{2}=0.99\end{array}$ & $\begin{array}{c}y=0.2966 x-0.1161 \\
R^{2}=0.99\end{array}$ & $\begin{array}{c}y=0.0524 x+ \\
0.0293 \\
R^{2}=0.99\end{array}$ & $\begin{array}{c}y=0.0149 x+ \\
0.0029 \\
R^{2}=0.99\end{array}$ \\
\hline Sensitivity coefficient, $\mu \mathrm{A} / \mathrm{mM}$ & 0.94 & 0.30 & 0.05 & 0.01 \\
\hline Minimal range of detection, $\mathrm{mM}$ & 0.05 & 0.05 & 1 & 0.5 \\
\hline Detection range, $\mathrm{mM}$ & $0.05-3$ & $0.05-6$ & $1-25$ & $0.5-25$ \\
\hline
\end{tabular}

* For this type of electrode the surface was additionally modified with MWCNTs (see methods).

One of the important characteristics of the assay is its specificity. To assess a partial specificity of the receptor element for a biosensor based on MWCNTs-modified electrodes, we examined signals for citric acid (within the concentration range of 0.06 to $0.90 \mathrm{mM}$ ) and ethanol (within the concentration range of 0.1 to $2.0 \mathrm{M}$ ). As shown in Figure 7, these compounds evoked no generation of useful signals. This is due, first, to the specificity of the enzyme we used, and, second, to the fact that the measurements were carried out at a zero potential of the measuring electrode. 
Table 3. Sensitivity and limit of detection for some glucose biosensors based on GOx.

\begin{tabular}{cccc}
\hline Biosensor Composition & Limit of Detection, $\mu \mathbf{M}$ & Sensivity & References \\
\hline Nafion/GOx/ZnO/ITO & 50 & $3.87 \mu \mathrm{A} / \mathrm{mM} \cdot \mathrm{cm}^{2}$ & {$[40]$} \\
\hline PEC/AuNPs/GOx/Au & 5 & $283.9 \mu \mathrm{A} / \log [$ glucose] & {$[41]$} \\
\hline $\begin{array}{c}\text { Poly(3,4-ethylenedioxythiophene) } \\
\text { nanofiber based glucose biosensor }\end{array}$ & 67.8 & $272.58 \mu \mathrm{A} / \mathrm{mM} \mathrm{cm}^{2}$ & {$[42]$} \\
\hline GOx/AgNPs/HNTs & 200 & $5.1 \mu \mathrm{A} / \mathrm{mM} \mathrm{cm}^{2}$ & {$[43]$} \\
\hline rGO/PDA/MOF/GOx & 0.3 & $9.6 \mu \mathrm{A} / \mathrm{mM} \mathrm{cm}^{2}$ & {$[44]$} \\
\hline p-MAA/Nafion/GOx & 10 & $12.0 \mu \mathrm{A} / \mathrm{mM} \mathrm{cm}^{2}$ & {$[45]$} \\
\hline PMCs/MWCNTs/GOx & 50 & $13.4 \mu \mathrm{A} / \mathrm{mM} \mathrm{cm}^{2}$ & This work
\end{tabular}

Note: ITO, indium tin oxide; PEC, polyelectrolyte complex; NP, nanoparticles; HNTs, halloysite nanotubes; rGO, reduced graphene oxide; PDA, polydopamine; MOF, metal-organic frameworks; p-mAA, poly-methacrylic acid.

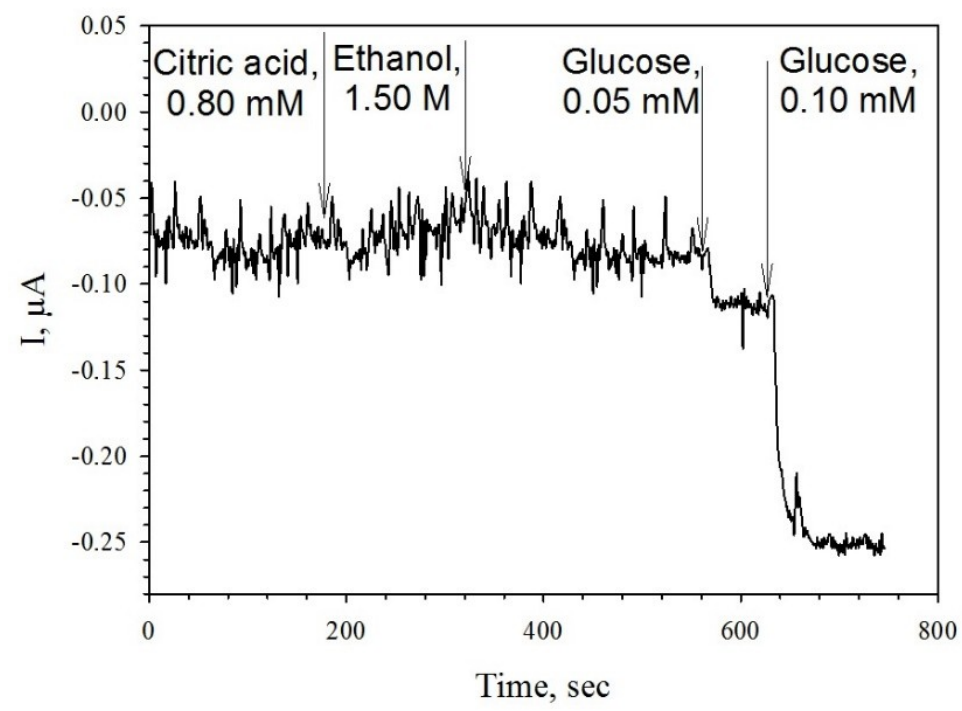

Figure 7. Amperometric signals of a PMCs/GOx/MWCNTs-modified biosensor upon addition of citric acid, ethanol, or glucose.

\section{Discussion}

The performed work aimed to study effects of modulating the bioelectrochemical properties of PMCs at their contact with MWCNTs. Polyelectrolyte microcapsules are objects of a rapidly developing field - polymer nanotechnology — and are widely used to form supramolecular structures. PMCs are, in fact, a structure formed by multilayer membranes that consist of polyelectrolytes.

PMCs are widely used in experimental and applied events. They make it possible to create containers for incapsulation of proteins, including enzymes, (sub)cellular structures, medicinal substances, and other high-molecular compounds. The incorporation of enzymes into PMCs leads to a significant rise in the lifetime of its active state. In this connection, it is topical to investigate their properties at their contact with a nanomaterial represented by MWCNTs.

This work was the first to show that such characteristics as impedance spectra of PMCs prove to be highly sensitive to the occurrence of MWCNTs. This sensitivity manifests itself by a significant decrease of the active constituent of the impedance at a modification with PMCs. On the whole, effects of a change in the physicochemical properties of multilayer polyelectrolyte membranes have been known for various electrode materials [46], including for modifications of multilayer polyelectrolyte membranes using MWCNTs, which make the base of the biosensor [32]. It should be noted that in earlier considered cases, the modification with MWCNTs was considered either for plane multilayer membranes or else for membranes formed from other classes of polyelectrolytes, e.g., osmium polymer [33] or chitosan [47]. The presented work first shows that, using MWCNTs, a significant change of the physical 
chemical properties of closed membrane structures can be obtained. It is shown that the decrease in the resistance of PMCs due to the inclusion of MWCNTs in its composition leads to an increase in the sensitivity of glucose biosensors and a decrease in their detection limit. The produced data of impedance measurements were supported by a study of the cyclic current-voltage dependences. Studies of a laboratory model of the biosensor enabled in the first approximation to assess the analytical parameters, which indicate a significant improvement of the characteristics.

We should note an important applied advantage that ensues from the preparation of closed microstructures as compared with the formation of plane structures. Closed cell-like microstructures act as a semiproduct, which enables creating a required product, e.g., a receptor element of the biosensor, from the available stock with minimal time expenses. Technology-wise, the development of such kinds of items from plane structures appears to be impossible. For this reason, separately fabricating and storing PMC capsules containing a biocatalyst and MWCNTs and then rapidly using them is a way of forming biosensors or else microbial fuel cell structures over small time periods, and does not require additional chemical reagents to treat the electrode surface before and after the measurement. As our research has shown, the obtained electrode composite demonstrates good reproducibility of voltammetric responses, as well as a low detection limit and high sensitivity for measuring glucose. Moreover, GOx is a suitable model biocatalyst for the further development of other enzyme bioelectrodes containing PMCs and nanomaterials. Composites presented in this paper may be used as membranes, whose properties can be controlled during production.

Author Contributions: Conceptualization, A.R. and Y.P.; Formal Analysis, Y.P., S.T., and A.D.; Funding Acquisition, V.K. (Vladimir Kolesov) and I.K.; Investigation, Y.P., S.T., and A.K., V.K. (Vadim Kashin) and A.M.; Methodology, S.T.; Project Administration, A.R. and V.K. (Vladimir Kolesov); Resources, V.K. (Vladimir Kolesov) and I.K.; Supervision, A.R.; Validation, V.K. (Vladimir Kolesov); Visualization, Y.P.; Writing-Original Draft, A.R., Y.P., and S.T.; Writing-Review and Editing, G.-J.W., V.K. (Vladimir Kolesov) and I.K.

Funding: The work was supported by the Russian Science Foundation (RSF) grant No 18-49-08005.

Acknowledgments: The work was supported by the Russian Science Foundation grant No18-49-08005. The authors acknowledge Victor Selivanov for providing linguistic help.

Conflicts of Interest: The authors declare no conflicts of interest.

\section{References}

1. Strawski, M.; Granicka, L.H.; Szklarczyk, M. Redox properties of polyelectrolyte multilayer modified electrodes: A significant effect of the interactions between the polyelectrolyte layers in the films. Electrochim. Acta 2017, 226, 121-131. [CrossRef]

2. Lalonde, J.; Margolin, A. Immobilization of enzymes. In Enzyme Catalysis in Organic Synthesis, 2nd ed.; Drauz, K., Waldmann, H., Eds.; WileyVCH Verlag GmbH: Weinheim, Germany, 2002; pp. 163-184. ISBN 3-527-29949-1.

3. Gemeiner, P. Enzyme Engineering: Immobilized Biosystems; Ellis Horwood, Ltd.: Chichester, UK, 1992.

4. Peyratout, C.S.; Dähne, L. Tailor-made polyelectrolyte microcapsules: From multilayers to smart containers. Angew. Chem. Int. Ed. 2004, 43, 3762-3783. [CrossRef] [PubMed]

5. Guzmán, E.; Mateos-Maroto, A.; Ruano, M.; Ortega, F.; Rubio, R.G. Layer-by-layer polyelectrolyte assemblies for encapsulation and release of active compounds. Adv. Colloid Interface Sci. 2017, 249, 290-307. [CrossRef]

6. Belbekhouche, S.; Charaabi, S.; Picton, L.; Le Cerf, D.; Carbonnier, B. Glucose-sensitive polyelectrolyte microcapsules based on (alginate/chitosan) pair. Carbohydr. Polym. 2018, 184, 144-153. [CrossRef] [PubMed]

7. Decher, G.; Hong, J.D. Buildup of ultrathin multilayer films by a self-assembly process, 1: Consecutive adsorption of anionic and cationic bipolar amphiphiles on charged surfaces. Makromol. Chem. Macromol. Symp. 1991, 46, 321-327. [CrossRef]

8. Decher, G. Fuzzy nanoassemblies: Toward layered polymeric multicomposites. Science 1997, 277, $1232-1237$. [CrossRef]

9. Brett, C.M.A. Perspectives and challenges for self-assembled layer-by-layer biosensor and biomaterial architectures. Curr. Opin. Electrochem. 2018, 12, 21-26. [CrossRef] 
10. Ivanov, A.; Davletshina, R.; Sharafieva, I.; Evtugyn, G. Electrochemical biosensor based on polyelectrolyte complexes for the determination of reversible inhibitors of acetylcholinesterase. Talanta 2019, 194, 723-730. [CrossRef] [PubMed]

11. Eremenko, A.V.; Varfolomeev, S.D.; Yaroslavov, A.A.; Pergushov, D.V.; Papkov, V.S.; Sigolaeva, L.V.; Kurochkin, I.N.; Zezin, A.B.; Tur, D.R.; Dubacheva, G.V.; et al. Nanostructured polyelectrolyte films for engineering highly sensitive tyrosinase biosensors: Specifics of enzyme-polyelectrolyte structures. Nanotechnol. Russ. 2008, 3, 221-227. [CrossRef]

12. Lin, C.; Chen, Q.; Yi, S.; Wang, M.; Regen, S.L. Polyelectrolyte multilayers on PTMSP as asymmetric membranes for gas separations: Langmuir-Blodgett versus self-assembly methods of anchoring. Langmuir 2014, 30, 687-691. [CrossRef]

13. Gribova, V.; Auzely-Velty, R.; Picart, C. Polyelectrolyte multilayer assemblies on materials surfaces: From cell adhesion to tissue engineering. Chem. Mater. 2012, 24, 854-869. [CrossRef]

14. Illergård, J.; Römling, U.; Wågberg, L.; Ek, M. Biointeractive antibacterial fibres using polyelectrolyte multilayer modification. Cellulose 2012, 19, 1731-1741. [CrossRef]

15. Lichter, J.A.; Van Vlietpa, K.J.; Rubner, M.F. Design of antibacterial surfaces and interfaces: Polyelectrolyte multilayers as a multifunctional platform. Macromolecules 2009, 42, 8573-8586. [CrossRef]

16. Larrañaga, A.; Lomora, M.; Sarasua, J.R.; Palivan, C.G.; Pandit, A. Polymer capsules as micro-/nanoreactors for therapeutic applications: Current strategies to control membrane permeability. Prog. Mater. Sci. 2017, 90, 325-357. [CrossRef]

17. Cerqueira, M.Â.; Pinheiro, A.C.; Ramos, O.L.; Silva, H.; Bourbon, A.I.; Vicente, A.A. Advances in Food Nanotechnology. In Emerging Nanotechnologies in Food Science; Elsevier: Boston, MA, USA, 2017; pp. 11-38. ISBN 9780323429801.

18. Montazer, M.; Harifi, T. Nanoencapsulation techniques for textile finishing. In Nanofinishing of Textile Materials; Woodhead Publishing: Sawston, UK, 2018; pp. 295-310. ISBN 9780081012505.

19. Balkundi, S.S.; Veerabadran, N.G.; Eby, D.M.; Johnson, G.R.; Lvov, Y.M. Encapsulation of bacterial spores in nanoorganized polyelectrolyte shells. Langmuir 2009, 25, 14011-14016. [CrossRef]

20. Ternovskij, V.I.; Chernohvostov, Y.u.V.; Fomkina, M.G.; Montrel, M.M. Electrometric sensor on the basis of the urease immobilized in polyelectrolytic microcapsules. Biofizika 2007, 52, 825-829.

21. Montrel, M.M.; Ternovskij, V.I.; Fomkina, M.G.; Petrov, A.I. Ultrathin Polymeric Covering, Way of His Production and Enzymatic Biosensor on Its Basis. Patent No. 2333231 2008. (In Russian)

22. Reshetilov, A.N.; Plekhanova, Y.V.; Tikhonenko, S.A.; Dubrovskii, A.V. Polyelectrolyte microcapsules with urease and paramagnetic particles as a basis for a potentiometric biosensor for determining urea. J. Anal. Chem. 2015, 70, 1368-1372. [CrossRef]

23. Yagodina, L.O.; Chernokhvostov, Yu.V. Immobilizatsiya acetilkholisterazi inkapsulatsiei v polimernix nano- i mikrokapsulah. Vestn. Kazan Technol. Univ. 2013, 16, 117-119.

24. Kazakova, L.I.; Sirota, N.P.; Sirota, T.V.; Shabarchina, L.I. The study of a fluorescent biosensor based on polyelectrolyte microcapsules with encapsulated glucose oxidase. Russ. J. Phys. Chem. A 2017, 91, 1828-1832. [CrossRef]

25. Šefčovičová, J.; Tkac, J. Application of nanomaterials in microbial-cell biosensor constructions. Chem. Pap. 2015, 69, 42-53. [CrossRef]

26. Ghasemi, M.; Daud, W.R.W.; Hassan, S.H.A.; Oh, S.E.; Ismail, M.; Rahimnejad, M.; Jahim, J.M. Nano-structured carbon as electrode material in microbial fuel cells: A comprehensive review. J. Alloys Compd. 2013, 580, 245-255. [CrossRef]

27. Cosnier, S.; Holzinger, M.; Le Goff, A. Recent advances in carbon nanotube-based enzymatic fuel cells. Front. Bioeng. Biotechnol. 2014, 2. [CrossRef]

28. Karimi, A.; Othman, A.; Uzunoglu, A.; Stanciu, L.; Andreescu, S. Graphene based enzymatic bioelectrodes and biofuel cells. Nanoscale 2015, 7, 6909-6923. [CrossRef]

29. Trifonov, A.; Herkendell, K.; Tel-Vered, R.; Yehezkeli, O.; Woerner, M.; Willner, I. Enzyme-capped relay-functionalized mesoporous carbon nanoparticles: Effective bioelectrocatalytic matrices for sensing and biofuel cell applications. ACS Nano 2013, 7, 11358-11368. [CrossRef]

30. Sugimoto, Y.; Kitazumi, Y.; Shirai, O.; Kano, K. Effects of mesoporous structures on direct electron transfer-type bioelectrocatalysis: Facts and simulation on a three-dimensional model of random orientation of enzymes. Electrochemistry 2017, 85, 82-87. [CrossRef] 
31. Gross, A.J.; Holzinger, M.; Cosnier, S. Buckypaper bioelectrodes: Emerging materials for implantable and wearable biofuel cells. Energy Environ. Sci. 2018, 11, 1670-1687. [CrossRef]

32. Barsan, M.M.; Brett, C.M.A. Graphene and carbon nanotube nanomaterials in layer-by-layer structured electrochemical enzymatic biosensors: A review. Stud. Univ. Babes Bolyai Chem. 2015, 60, 31-52.

33. Gao, Q.; Guo, Y.; Zhang, W.; Qi, H.; Zhang, C. An amperometric glucose biosensor based on layer-by-layer GOx-SWCNT conjugate/redox polymer multilayer on a screen-printed carbon electrode. Sens. Actuators B Chem. 2011, 153, 219-225. [CrossRef]

34. Gao, Q.; Guo, Y.; Liu, J.; Yuan, X.; Qi,H.; Zhang, C. A biosensor prepared by co-entrapment of a glucose oxidase and a carbon nanotube within an electrochemically deposited redox polymer multilayer. Bioelectrochemistry 2011, 81, 109-113. [CrossRef]

35. Karyakin, A.A.; Gitelmacher, O.V.; Karyakina, E.E. A high-sensitive glucose amperometric biosensor based on prussian blue modified electrodes. Anal. Lett. 1994, 27, 2861-2869. [CrossRef]

36. Petrov, A.I.; Volodkin, D.V.; Sukhorukov, G.B. Protein-calcium carbonate coprecipitation: A tool for protein encapsulation. Biotechnol. Prog. 2005, 21, 918-925. [CrossRef]

37. Kazakova, L.I.; Dubrovskii, A.V.; Moshkov, D.A.; Shabarchina, L.I.; Sukhorukov, B.I. An electron microscopy study of the structure of polyelectrolyte microcapsules containing protein and containing no protein. Biofizika 2007, 52, 850-854.

38. Fiorito, P.A.; Brett, C.M.A.; Córdoba De Torresi, S.I. Polypyrrole/copper hexacyanoferrate hybrid as redox mediator for glucose biosensors. Talanta 2006, 69, 403-408. [CrossRef]

39. Li, J.; Qiu, J.D.; Xu, J.J.; Chen, H.Y.; Xia, X.H. The synergistic effect of prussian-blue-grafted carbon nanotube/poly(4-vinylpyridine) composites for amperometric sensing. Adv. Funct. Mater. 2007, 17, 1574-1580. [CrossRef]

40. Ridhuan, N.S.; Abdul Razak, K.; Lockman, Z. Fabrication and Characterization of Glucose Biosensors by Using Hydrothermally Grown ZnO Nanorods. Sci. Rep. 2018, 8, 13722. [CrossRef]

41. Rassas, I.; Braiek, M.; Bonhomme, A.; Bessueille, F.; Raffin, G.; Majdoub, H.; Jaffrezic-Renault, N. Highly sensitive voltammetric glucose biosensor based on glucose oxidase encapsulated in a chitosan/kappa-carrageenan/gold nanoparticle bionanocomposite. Sensors 2019, 19, 154. [CrossRef]

42. Çetin, M.Z.; Camurlu, P. An amperometric glucose biosensor based on PEDOT nanofibers. RSC Adv. 2018, 8, 19724-19731. [CrossRef]

43. Kumar-Krishnan, S.; Hernandez-Rangel, A.; Pal, U.; Ceballos-Sanchez, O.; Flores-Ruiz, F.J.; Prokhorov, E.; Arias De Fuentes, O.; Esparza, R.; Meyyappan, M. Surface functionalized halloysite nanotubes decorated with silver nanoparticles for enzyme immobilization and biosensing. J. Mater. Chem. B 2016, 4, 2553-2560. [CrossRef]

44. Hou, C.; He, F.; Liu, M.; Wang, Y.; Li, X.; Zhang, Y. Preparation of graphene nano-sheet bonded PDA/MOF microcapsules with immobilized glucose oxidase as a mimetic multi-enzyme system for electrochemical sensing of glucose. J. Mater. Chem. B 2016, 4, 3695-3702.

45. Hervás Pérez, J.P.; López-Ruiz, B.; López-Cabarcos, E. Synthesis and characterization of microparticles based on poly-methacrylic acid with glucose oxidase for biosensor applications. Talanta 2016, 149, 310-318. [CrossRef]

46. Chapel, J.P.; Berret, J.F. Versatile electrostatic assembly of nanoparticles and polyelectrolytes: Coating, clustering and layer-by-layer processes. Curr. Opin. Colloid Interface Sci. 2012, 17, 97-105. [CrossRef]

47. Ma, L.; Lu, W.; Wen, J. Encapsulation of lactate dehydrogenase in carbon nanotube doped alginate-chitosan capsules. J. Mol. Catal. B Enzym. 2009, 56, 102-107. [CrossRef]

(C) 2019 by the authors. Licensee MDPI, Basel, Switzerland. This article is an open access article distributed under the terms and conditions of the Creative Commons Attribution (CC BY) license (http://creativecommons.org/licenses/by/4.0/). 